\title{
Cost-Sharing for Part B Chemotherapy Drugs in Medicare Advantage Plans: an Administrative Data Analysis
}

\author{
Laura M. Keohane, PhD and Christopher J. Finch, BA \\ Department of Health Policy, Vanderbilt University School of Medicine, Nashville, TN, USA.
}

J Gen Intern Med 34(7):1119-20

DOI: $10.1007 / \mathrm{s} 11606-019-04863-5$

(c) Society of General Internal Medicine 2019

\section{INTRODUCTION}

In 2017, a third of Medicare beneficiaries chose a Medicare Advantage (MA) managed care plan. ${ }^{1}$ These plans cover traditional Medicare services and optional extra benefits like dental care. Unlike traditional Medicare, these plans can restrict provider networks and require prior authorization. Cancer patients in MA plans have historically had slightly higher out-of-pocket costs (excluding premiums) than traditional Medicare beneficiaries with supplemental insurance. ${ }^{2}$

MA members' out-of-pocket costs for cancer treatment may be affected by several recent federal regulations intended to prevent patients with expensive health needs from avoiding MA plans due to high cost-sharing requirements. ${ }^{3}$ Since 2011, almost all MA plans are required to offer out-of-pocket limits (\$6700 maximum) that apply to cost-sharing for all services except Part D drugs. ${ }^{4}$

Cost-sharing for chemotherapy drugs administered in an outpatient setting or clinical office is also regulated. Since 2011, MA plans can charge no more than what traditional Medicare Part B would charge for this benefit: $20 \%$ coinsurance. Alternatively, MA plans can charge copayments no greater than $\$ 75$. (Similar restrictions apply to other Part B drugs.) We examined how MA plans' cost-sharing requirements for Part B chemotherapy drugs have changed over the past 10 years (2008-2018) as these regulations took effect.

\section{METHODS}

The Centers for Medicare and Medicaid Services (CMS) publicly reports MA plans' annual cost-sharing information, monthly enrollment statistics, and plan type. ${ }^{5}$ We combined these data sets for the years 2008-2018 to identify Part B chemotherapy benefits for members of MA Health Maintenance Organization and Preferred Provider Organization plans. Plan enrollment numbers are based on December totals for the years 2008-2017 and February for 2018. We excluded plans sponsored by groups (including employers and unions) , Special Needs Plans, and plans with fewer than 10 enrollees.

Published online February 25, 2019
Between December 2008 and February 2018, the population size increased from 5,136,964 enrollees in 1627 plans to $13,084,614$ enrollees in 2158 plans, or a $155 \%$ increase in the total number of MA enrollees in these plans.

\section{RESULTS}

In 2008, $6 \%$ of MA enrollees had Part B chemotherapy costsharing requirements that exceeded either $20 \%$ coinsurance or $\$ 75$ copayments (Fig. 1). By 2010, all plans charged no more than the amounts specified in the 2011 and 2012 regulations.

Over the past decade, plans shifted towards charging the maximum allowable cost-sharing for Part B chemotherapy drugs. In 2018, $87 \%$ of enrollees had $20 \%$ coinsurance for this benefit, compared to $31 \%$ in 2008 .

This shift towards coinsurance coincided with fewer plans offering full coverage or copayments for Part B chemotherapy drugs. The percentage of beneficiaries with no cost-sharing for these drugs declined from $30 \%$ in 2008 to $9 \%$ in 2018. Only $1 \%$ of beneficiaries had copayments in 2018 , down from $24 \%$ in 2008 .

\section{DISCUSSION}

As the MA population expanded, cost-sharing requirements for Part B chemotherapy drugs increased. Almost 9 out of 10 current MA enrollees have $20 \%$ coinsurance for Part B chemotherapy drugs. Unlike traditional Medicare enrollees, MA enrollees cannot purchase supplemental plans to cover cost-sharing requirements. Part B chemotherapy drugs, though, are subject to mandatory caps in MA plans on overall cost-sharing (excluding Part D drugs). With coinsurance, patients' out-of-pocket costs will vary by drug price. For example, total spending per claim for the 10 most commonly prescribed chemotherapy drugs in traditional Medicare Part B ranged from $\$ 14$ for fluorouracil to $\$ 6370$ for rituximab in $2016 .{ }^{6}$ With $20 \%$ coinsurance, out-of-pocket costs per claim would range from $\$ 3$ for fluorouracil to $\$ 1274$ for rituximab until the out-of-pocket limit ( $\max \$ 6700$ ) is reached.

Starting in 2019, CMS will allow Medicare Advantage plans to implement step therapy for Part B drugs, which underscores the need to understand members' cost-sharing requirements. MA plans may require its members to try the plan's preferred drug or demonstrate it is not appropriate before alternative drugs are covered. This strategy may allow plans to bargain for better 


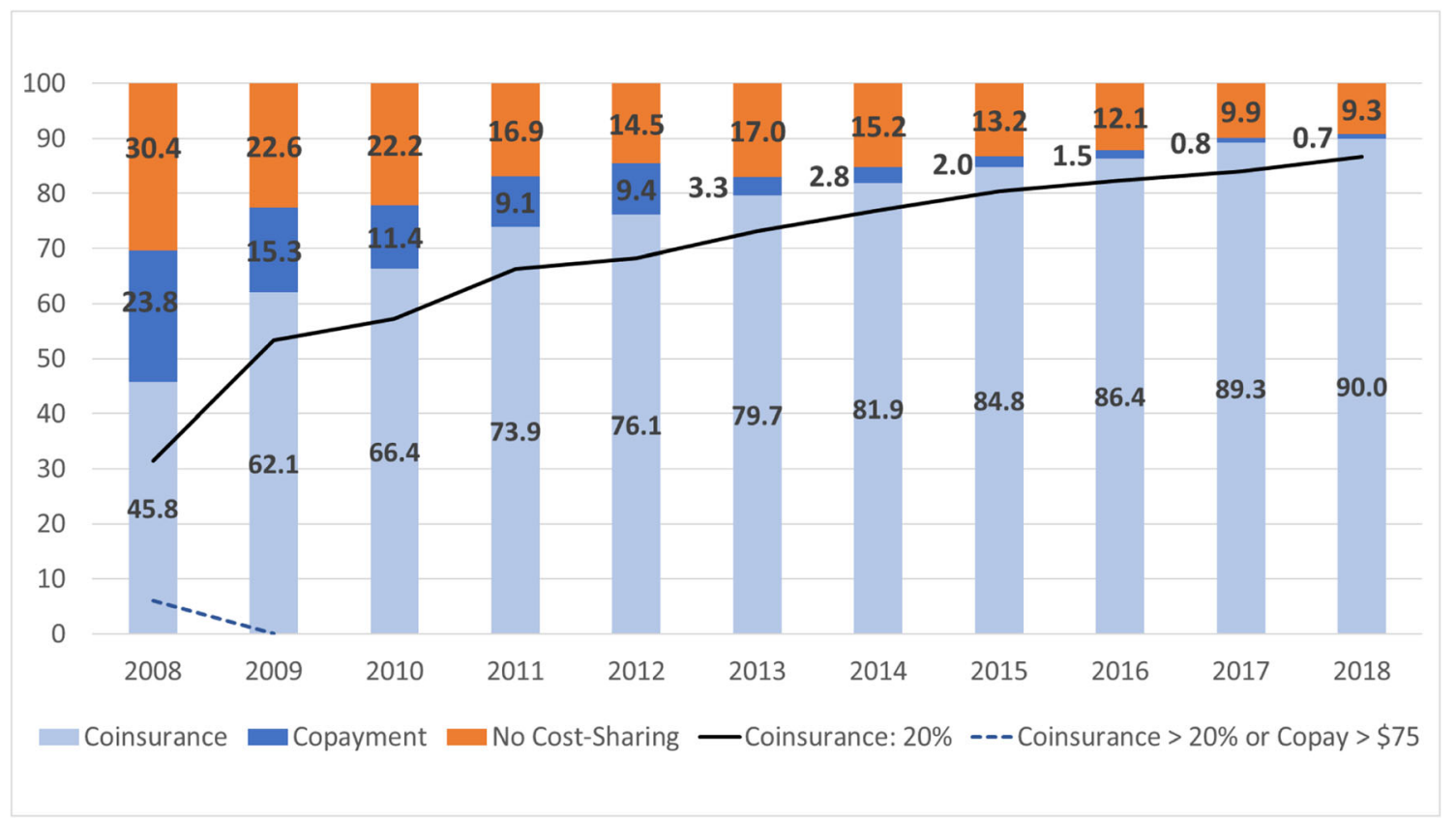

Fig. 1 Percent of Medicare Advantage enrollees by Part B chemotherapy cost-sharing requirements. Notes: Authors' analysis of Centers for Medicare and Medicaid Services data on Medicare Advantage plan enrollment and benefits. Population includes beneficiaries enrolled in Health Maintenance Organizations and Preferred Provider Organizations and excludes beneficiaries enrolled in group plans, Special Needs Plans, and plans with fewer than 10 enrollees.

drug prices for preferred drugs, which could reduce members' out-of-pocket coinsurance, but members may also see large differences in coinsurance between preferred and nonpreferred drugs.

Regulations have protected beneficiaries from facing exceptionally high cost-sharing for Part B chemotherapy drugs, but clinicians should be aware that MA enrollees may still face significant out-of-pocket costs, especially at the beginning of treatment or the start of the calendar year.

Acknowledgments: Dr. Keohane's effort on this study was supported by a Career Development Award from the National Institute on Aging (K01AG058700).

Corresponding Author: Laura M. Keohane, PhD; Department of Health Policy, Vanderbilt University School of Medicine, Nashville, TN, USA (e-mail: laura.keohane@vanderbilt.edu).

Compliance with Ethical Standards:

Conflict of Interest: The authors declare that they do not have a conflict of interest.

Publisher's Note: Springer Nature remains neutral with regard to jurisdictional claims in published maps and institutional affiliations.

\section{REFERENCES}

1. Jacobson G, Damico A, Neuman T, and Gold M. Medicare Advantage 2017 Spotlight: Enrollment Market Update. Available at: https://www.kff. org/medicare/issue-brief/medicare-advantage-2017-spotlight-enrollment-market-update/. Accessed October 29, 2018.

2. Narang AK, Nicholas $\mathbf{L}$. Out-of-pocket spending and financial burden among medicare beneficiaries with cancer. JAMA Oncology. 2017;3(6):757-65.

3. Centers for Medicare and Medicaid Services. Medicare program; policy and technical changes to the Medicare Advantage and Medicare prescription drug benefit programs; final rule: 6. Maximum Allowable Cost Sharing Amount for Medicare Parts A and B Services and Prescription Drugs 2010. Available at: http://www.gpo.gov/fdsys/pkg/FR-2010-04-15/pdf/20107966.pdf. Accessed October 29, 2018.

4. Keohane LM, Grebla RC, Mor V, Trivedi AN. Medicare Advantage Members' Expected Out-Of-Pocket Spending for Inpatient And Skilled Nursing Facility Services. Health Aff (Millwood). 2015;34(6):1019-1027.

5. Centers for Medicare and Medicaid Services. Medicare Advantage/Part D Contract and Enrollment Data. Available at: https://www.cms.gov/Research-Statistics-Data-and-Systems/Statistics-Trends-and-Reports / MCRAdvPartDEnrolData/index.html. Accessed October 29, 2018.

6. Centers for Medicare and Medicaid Services. Medicare Part B Drug Spending Dashboard. Available at: https://www.cms.gov/Research-Statistics-Data-and-Systems/Statistics-Trends-and-Reports/Information-onPrescription-Drugs/Downloads/Medicare_PartB_Drug_Spending_Data. zip. Accessed October 29, 2018. 